\section{Argentina: Onset Addiction Occurs at age 8}

Received: August 31, 2015; Accepted: September 03, 2015; Published: September 11,2015

In the World Drug Report 2015, prepared by the United Nations, it noted that Argentina is the largest consumer of cocaine in South America [1]. National and international reports revealed that 10 percent of people in Argentina are committed to some kind of toxic substance, and that Argentina became the second largest consumer of cocaine per capita in the world. It was also found that the age of onset addiction occurs at age 8 [2].

A report by the Secretariat on Addictions of the province of Buenos Aires said that at age 13 starts in consumption $20.7 \%$ of young people; 15 years 19.2\%; at 12 years $11.6 \%$. The low age at which teens start Argentine insertion in the drug, is undoubtedly the main aspect that the authorities should take to prevent start changing reality of some concern. The agency's report also studied what the place or environment in which the child begins to consume narcotics, and the reality brand that is the main street $(69.2 \%)$, followed far behind by the home $(7.6 \%)$, school $(7.0 \%)$, the bars $(4.4 \%)$, and school $(3.0 \%)[3,4]$.

Without doubt, the economic crisis in Argentina in 2001 has resulted in the expansion and consolidation of the crime of drug trafficking, increased criminal violence, increased police corruption, the expansion of illegal drug-related economies, control and co-opting politicians, judges, rulers and social leaders by criminal groups, and the prevailing criminalization of consumers and smaller dealers belonging to the lowest social classes.

What has been observed in Argentina, but is not unique to this country, it is that the police protection to drug traffickers embryonic set the necessary condition for the expansion and stabilization of the illegal drug market, because it enabled and ensured the deployment and essential territorial domain [5].

In episodes of police corruption, problems of coordination, control and efficiency in the performance of the federal police system are added. This system is composed of four police agencies (the Federal Police Argentina, the National Gendarmerie, the Naval Prefecture Argentina and Airport Security Police). Each of these officers includes specialized areas in drug control. The problem is that the work carried out criminal intelligence and investigative actions on drug trafficking and independently segmented [6]. These trends demonstrate remarkable three

\section{Carlos J. Rubinstein}

\author{
Carlos J. Rubinstein, Professor, Faculty of \\ Medicine, Universidad de Buenos Aires, \\ Argentina
}

\author{
Corresponding author: \\ Carlos J. Rubinstein* \\ $\equiv$ rubidoc@gmail.com
}

Professor, Faculty of Medicine, Universidad de Buenos Aires, Argentina.

Citation: Rubinstein CJ. Argentina: Onset Addiction Occurs at age 8. J Drug Abuse. 2016, 2:1.

institutional gaps. First, the absence of an updated picture of the situation and comprehensive organized crime in the country and in particular drug trafficking, to account, at the strategic level, aspects of drug trafficking in Argentina with a view to formulating policies state and, at the tactical level, the activities and concrete actions of organized criminal groups with a view to a police response. Second, the absence of a superior agency or organization specializing in drug control to concentrate on the one hand, the responsibilities of formulating policies and strategies to control organized crime and government on the other, the work of driving the institutional system responsible for its implementation, especially in public security and police intervention. The third institutional vacuum is the lack of a unified and specialized police operation in the control of organized crime (and within drug trafficking), which, among other things, has reproduced the institutional fragmentation reflected on the historical trend whereby each police force or body, or each sector or grouping of a single police force, formulate and implement their own strategies and actions to control drug trafficking.

This reveals that in the city of Buenos Aires, who in the past boasted that Europe in South America, today similar social events recorded to other Latin American cities, involving the structuring of extended criminal networks and circuits under high profitability protection and participation of the police and the state itself. 


\section{References}

1 United Nations Office on Drugs and Crime. World Drug Report 2015

2 Scientific Advisory Committee on control of Illicit Traffic in Narcotic Drugs, Psychotropic Substances and Complex Criminality: The comprehensive reform of the Law on Narcotic Drugs and the identification of social policy, Ministry of Justice, Security and Human Rights, Buenos Aires, 2014.

3 Argentine Drug Observatory of the Secretariat of Programming for the Prevention of Drug Abuse and Drug Trafficking, trend in consumption of psychoactive substances in Argentina from 2004 to 2010: Population of $16-65$ years (2011)

4 Argentine Drug Observatory of the Secretariat of Programming for the Prevention of Drug Abuse and Drug Trafficking, Fifth National Survey of High School Students (2013)

5 Tokatlian, J. Globalization, drug trafficking and violence. Seven trial Colombia, Grupo Editorial Norma, Buenos Aires, 2000

6 Sain, M. The failure of the control of illegal drugs in Argentina. New Company No 222, July-August 2009, ISSN: 0251-3552 